\title{
Modelling the formation of organic particles in the atmosphere
}

\author{
T. Anttila ${ }^{1,2}$, V.-M. Kerminen ${ }^{1}$, M. Kulmala ${ }^{2}$, A. Laaksonen ${ }^{3}$, and C. D. O'Dowd ${ }^{4}$ \\ ${ }^{1}$ Finnish Meteorological Institute, Air Quality Research, Sahaajankatu 20E, FIN-00880 Helsinki, Finland \\ ${ }^{2}$ University of Helsinki, Department of Physical Sciences, P.O. Box 64, FIN-00014 University of Helsinki, Helsinki, Finland \\ ${ }^{3}$ University of Kuopio, Department of Applied Physics, P.O. Box 1627, FIN-70211, Kuopio, Finland \\ ${ }^{4}$ Department of Experimental Physics, National University of Ireland, Galway, University Road, Galway, Ireland
}

Received: 7 November 2003 - Published in Atmos. Chem. Phys. Discuss.: 8 December 2003

Revised: 1 March 2004 - Accepted: 26 June 2004 - Published: 6 July 2004

\begin{abstract}
Particle formation resulting from activation of inorganic stable clusters by a supersaturated organic vapour was investigated using a numerical model. The applied aerosol dynamic model included a detailed description of the activation process along with a treatment of the appropriate aerosol and gas-phase processes. The obtained results suggest that both gaseous sulphuric acid and organic vapours contribute to organic particle formation in continental background areas. The initial growth of freshly-nucleated clusters is driven mainly by condensation of gaseous sulphuric acid and by a lesser extent self-coagulation. After the clusters have reached sizes of around $2 \mathrm{~nm}$ in diameter, low-volatile organic vapours start to condense spontaneously into the clusters, thereby accelerating their growth to detectable sizes. A shortage of gaseous sulphuric acid or organic vapours limit, or suppress altogether, the particle formation, since freshly-nucleated clusters are rapidly coagulated away by pre-existing particles. The obtained modelling results were applied to explaining the observed seasonal cycle in the number of aerosol formation events in a continental forest site.
\end{abstract}

\section{Introduction}

As was recently highlighted by the Intergovernmental Panel on Climate Change (IPCC), interactions of aerosols with the atmosphere need to be quantified in order to assess reliably the impact of anthropogenic activities to the climate (IPCC, 2001). This is necessitated by the fact that aerosols exert a strong effect on the radiative properties of the atmosphere by scattering incoming solar radiation and by acting as cloud condensation nuclei, thereby modifying the cloud albedo and lifetime. These effects depend considerably on the number

Correspondence to: T. Anttila

(Tatu.Anttila@fmi.fi) concentration of atmospheric aerosol populations along with their size and chemical composition. Due to this sensitivity, a realistic treatment of the aerosol-climate interactions in global climate models requires accurate knowledge on different source mechanisms for atmospheric aerosols.

Atmospheric aerosols are produced both by direct emissions such as fossil-fuel combustion or wind (primary particle production) and by gas-to-particle conversion (secondary particle production). Globally, both of these pathways are expected to be important, since secondary particle production has also been observed to take place in a number of different atmospheric environments (Clarke, 1992; Covert et al., 1992; Weber et al., 1999; Birmili and Wiedensohler, 2000; Harrison et al, 2000; O'Dowd, 2001). However, while the primary aerosol sources can be reasonably well characterized, the exact mechanisms underlying the secondary aerosol formation are far from being understood.

There are strong reasons to believe that a first step in the secondary particle formation is nucleation which produces nanometer-size, thermodynamically stable clusters (TSCs) (e.g. Kulmala et al., 2000). Under favourable conditions, this is followed by the growth of TSCs to detectable sizes so that an apparent particle formation event can be observed. The bulk growth of TSCs and subsequently formed particles in the atmosphere is mainly explained by condensation of organic vapours (Marti et al., 1997; Kavouras et al., 1998; Leaitch et al., 1999; Yu et al., 1999; Kerminen et al., 2000; Kulmala et al., 2001a), even though sulphuric acid is expected to drive particle formation under certain circumstances (Birmili et al., 2000). There are also indications that nanometer-size particles formed in the atmosphere might be organic, or that they would have a major organic fraction (O'Dowd et al., 2002) as well as being well soluble in water (Hämeri et al., 2001). What is lacking, however, is a detailed explanation for the formation of organic particles in the atmosphere that would account for the different physicochemical processes involved. 


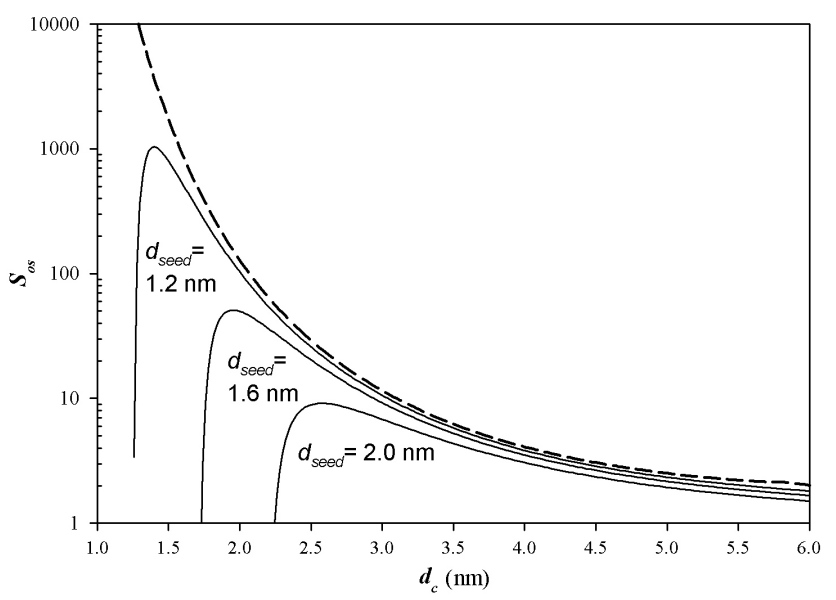

Fig. 1. The equilibrium saturation ratio of a water-soluble organic vapour above a cluster surface as a function of the cluster diameter $d_{c}$. The inorganic core inside the cluster has a diameter $d_{\text {seed }}$. A respective Kelvin term curve is also shown (dash-dot-line). The ambient temperature and relative humidity were assumed to be equal to $288 \mathrm{~K}$ and $80 \%$, respectively.

In this modelling study, we investigate in detail how organic particles are formed in the atmosphere. Our main goals are to present a mechanism explaining the growth of nanometer-size clusters by condensation of organic vapours, and to identify the factors limiting the production of organic particles with a particular attention paid to the relative roles played by organic vapours and gaseous sulphuric acid in this process.

The paper is organized as follows. First, we present an application of a theory describing activation of nanometersize stable clusters by a supersaturated organic vapour. By coupling it with a relatively simple box-model, we then investigate organic particle formation taking place in the atmosphere. Finally, we apply the obtained results to explaining seasonal variation in the number of aerosol formation events that has been observed during continuous measurements carried out at a continental forest site in Finland.

\section{Activation of freshly-nucleated clusters by an organic vapour}

It has been suggested that organic particles are formed in the atmosphere via condensation of organic vapours onto freshly-nucleated inorganic clusters (e.g. Kulmala et al., 2000). In principle, organic vapours could also participate in nucleation, even though it is quite uncertain whether this can take place under real atmospheric conditions (Gao et al., 2001; Bonn et al., 2002). Here we do not explore this pathway but focus on explaining how organic particles are formed from inorganic clusters.

\subsection{Approach}

Here only a short description of the applied framework is given because a detailed description was presented in our previous paper (Kulmala et al., 2004). Briefly, it is based on the traditional Köhler theory with two fundamental differences: 1) the activating droplets are nanometer-size clusters comprising of an inorganic salt and water, and 2) the activating vapour is a water-soluble organic vapour. The thermodynamic equilibrium for water (wat) and the water-soluble organic vapour $(o s)$ are determined by the following equations (Laaksonen et al., 1998):

$S_{o s, e q}=x_{o s} \times \gamma_{o s} \times \exp \left(\frac{a_{o s}}{d_{c}}\right)$,
$S_{w a t, e q}=x_{w a t} \times \gamma_{w a t} \times \exp \left(\frac{a_{w a t}}{d_{c}}\right)$

where $a_{i}=4 \sigma v_{i} / R T$. Here the subscript $i$ denotes either the organic species or water, $S_{i, e q}$ is the equilibrium saturation ratio, $x_{i}$ is the mole fraction and $\gamma_{i}$ activity coefficient of $i, a_{i}$ corresponds to the Kelvin term, $d_{c}$ is the droplet diameter, $\sigma$ is the surface tension, $v_{i}$ is the molecular volume of the compound $i, R$ is the universal gas constant $\left(8.315 \mathrm{~J} \mathrm{~mol}^{-1} \mathrm{~K}^{-1}\right)$ and $T$ is the temperature.

Simultaneous solution of the above-presented equilibrium equations requires that the values of the activity coefficients $\gamma_{o s}$ and $\gamma_{w a t}$ as well as the surface tension are estimated. To this end, we have applied a thermodynamic model that makes possible to treat a multi-component system as a pseudobinary one (Petersen et al., 2001). In this case the ionic salt and associated water form together one component and the organic compound forms the second component. The pseudobinary activity coefficients are described using Van Laar equations, and the activity coefficient of water is obtained by multiplying the pseudobinary activity coefficient by that of water in a pure water-ammonium bisulphate solution (Tang and Munkelwitz, 1994). For the surface tension, we applied equations which have been used to fit surface tensions of aqueous supercooled carboxylic acid solutions (Alvarez et al., 1997). Overall, the system contains 5 free parameters, including the size of the organic molecule which we set equal to $2.25 \times 10^{-28} \mathrm{~m}^{3}$. Since the actual organic species is unknown, so are its thermodynamic properties. Nevertheless, in order to estimate these properties we utilise hygroscopic growth data for $10 \mathrm{~nm}$ particles measured at continental forest site (Hämeri and Väkevä, 2000). These particles are expected to comprise 20-30\% ammonium bisulphate and 70$80 \%$ organic species (Kulmala et al., 2004). Using this chemical composition and the measured hygroscopic growth factors of the aerosol (i.e. growth from dry conditions to relative humidities between $70 \%$ and $90 \%$ ), we estimated the values of the thermodynamic parameters from the experimental data.

After the values of the thermodynamic parameters have been fixed, equilibrium saturation ratios for the water-soluble 
organic vapour can be calculated by solving the abovepresented equilibrium equations using an iterative procedure (Fig. 1). Analogous to the traditional application of the Köhler theory, nucleated clusters become activated, i.e. they start growing by spontaneous condensation after the saturation ratio of a condensing organic vapour, $S_{o s}$, exceeds its peak equilibrium value. A comparison of the Kelvin term with the equilibrium curves shows that homogeneous nucleation of the organic vapour requires saturation ratios that are typically several orders of magnitude higher than those required for cluster activation, making the latter pathway more favourable for particle formation. Furthermore, the peak equilibrium saturation ratio decreases very strongly as the size of an inorganic seed in a cluster increases: activation of clusters having initial diameters of 1.2 and $2 \mathrm{~nm}$ requires saturation ratios around $10^{3}$ and 10 , respectively. However, the saturation ratios required for cluster activation and subsequent growth exceed clearly unity in any case, rising the question "is it possible that any organic vapour reaches such high supersaturations under real atmospheric conditions?". A quantitative answer to this question is given in the next section.

2.2 Factors determining the saturation ratio of an organic vapour

Whether an atmospheric cluster population will become activated by a condensing organic compound depends on how high saturation ratio of the organic compound, $S_{o s}$, reaches. This depends on complex interactions between a condensing organic vapour, freshly-formed clusters and a pre-existing aerosol population. In this section, we discuss the factors affecting $S_{o s}$ and introduce an explicit equation describing its time development.

Insight into the considered dynamics can be gained by considering the differences between the cloud droplet activation caused by the condensation of water vapour and the activation of nanometer-size particles caused by the condensation of a supersaturated organic vapour (Kulmala et al., 2004). First, the gas-phase concentration of water vapour is around $10^{16}-10^{17}$ molecules $\mathrm{cm}^{-3}$, whereas that of the condensing organic vapour is estimated to be between $10^{6}$ $10^{8}$ molecules $\mathrm{cm}^{-3}$ (Kulmala et al., 2001b; Dal Maso et al., 2002). Second, the activating cloud droplets consume effectively the available water vapour in a cloud updraft, thereby limiting the activation process itself. Therefore the supersaturation of water vapour does not reach very large values during a cloud formation, but stays typically below $0.1 \%$ (e.g. Seinfeld and Pandis, 1998). In contrast, the loss rate of the organic vapour to aerosol particles is determined rather by background particles than nanometer-size clusters and secondary particles. Therefore the saturation ratios reached by the condensing organic vapour differ substantially from those of water vapour. As the following demonstrates, this argument can be justified quantitatively.
The time development of the condensing organic vapour concentration, $C_{o s}$, is described by the following equation:

$\frac{d C_{o s}}{d t}=Q-C S \times C_{o s}$.

Here $Q$ (molecules $\mathrm{cm}^{-3} \mathrm{~s}^{-1}$ ) is the production rate of the condensing organic vapour and $C S\left(\mathrm{~s}^{-1}\right)$ is a so-called condensation sink that describes the loss rate of a condensing vapour onto the particle surfaces (see, e.g. Kulmala et al., 2001b). Because of their larger size, pre-existing particles make a dominant contribution to the value of $C S$ rather than secondary particles. We assume here that the organic vapour condenses irreversibly into pre-existing particles, i.e. its saturation vapour pressure is equal to zero over the surfaces of these particles. This assumption is justified in Sect. 3 .

Equation for the time development of the saturation ratio $S_{o s}=C_{o s} / C^{0}$ easily follows from (2):

$\frac{d S_{o s}}{d t}=\frac{Q}{C^{0}}-C S \times S_{o s}-\frac{S_{o s}}{C^{0}} \times \frac{d C^{0}}{d t}$,

where $C^{0}$ is the saturation vapour concentration of the organic vapour as a pure compound. If $Q, C^{0}$ and $C S$ do not change too rapidly, $S_{o s}$ will reach a quasi-steady state, $S_{o s, s s}$. In order to a give a simple expression to this quantity, we neglect the time dependence of $C^{0}$ (a more detailed discussion on this issue is postponed to Section 4.5). By doing this and setting the left-hand side of (3) equal to zero, the following equation for $S_{o s, s s}$ is obtained:

$S_{o s, s s}=\frac{Q}{C S \times C^{0}}=\frac{C_{o s, s s}}{C^{0}}$.

Here $C_{o s, s s}=Q / C S$ is the steady-state concentration of the organic vapour. From Eq. (4) it is seen that under conditions where $S_{o s}$ follows closely its steady state value, $S_{o s}$ will peak when the ratio $Q / C S$ reaches its maximum.

It is instructive to apply (4) in estimating whether $S_{\text {os }}$ may exceed the maximum equilibrium saturation ratios over the surfaces of clusters having a diameter between 1$2 \mathrm{~nm}$ (Sect. 2.1). First, the estimated values for $Q$ are $\sim 10^{5}$ molecules $\mathrm{cm}^{-3} \mathrm{~s}^{-1}$ during aerosol formation events taking place at a remote continental site (Kulmala et al., 2001b; Dal Maso et al., 2002). The values for $C S$ are typically of order of $0.001 \mathrm{~s}^{-1}$ in the same site. Finally, $C^{0}$ of the condensing organic vapour has been estimated to be $<10^{6}-10^{7}$ molecules $\mathrm{cm}^{-3}$ (Kulmala et al., 1998; Kerminen et al., 2000; Anttila and Kerminen, 2003; Bonn and Moortgat, 2003). Inserting these values into Eq. (4), it is seen that $S_{o s}$ obtains values $>10-100$ during aerosol formation events. It can be thus concluded that the estimated value range of $S_{o s}$, derived from ambient data and independent modelling results, is consistent with the peak equilibrium saturation ratios shown in Fig. 1. This comparison indicates that the activation of nanometer-size clusters can take place under real atmospheric conditions, motivating a deeper study of the activation dynamics. 
According to Eq. (4), pre-existing particles play a central role in the time development of $S_{o s}$. In addition, these particles affect the number concentration of both newly formed clusters and particles via coagulational scavenging (Kerminen et al., 2001). Because the rate of the coagulational scavenging decreases rapidly as the newly formed clusters and particles grow, the effects of growth and coagulation processes are interconnected and have to be quantified using an appropriate numerical model.

\section{Model description}

The numerical model employed in this study couples the framework described in the previous section with a box model simulating the time development of an atmospheric aerosol population. Nucleation and coagulation are included, as well as the production of condensing vapours and their transfer between the gas and aerosol phase. Meteorological parameters included in the model are the temperature and relative humidity. While the model is in some respects highly simplified, it is still detailed enough to provide an overall picture on the activation dynamics of nanometer-size clusters in the atmosphere. In the following we describe briefly how the discussed processes are implemented in the model.

\subsection{Gas-phase chemistry}

The modelled gas-phase chemistry includes the formation of sulphuric acid and condensing organic compound. Sulphuric acid is produced via the oxidation of $\mathrm{SO}_{2}$ by $\mathrm{OH}$ radicals with a reaction rate constant equal to $1 \times 10^{-12}$ molecules ${ }^{-1} \mathrm{~cm}^{3}$. The $\mathrm{SO}_{2}$ concentration is assumed to be temporally constant, whereas the $\mathrm{OH}$ radical concentration follows a diurnal cycle: $[\mathrm{OH}]=[\mathrm{OH}]_{\max } \exp \left[-\left((t-12) / \tau_{\mathrm{OH}}\right)^{2}\right]$. Here $t$ is the local time in hours and $\tau_{\mathrm{OH}}$ describes how rapidly the $\mathrm{OH}$ radical concentration decreases from its maximum value, $[\mathrm{OH}]_{\max }$, which is reached at noon. The values of the parameters $[\mathrm{OH}]_{\max }$ and $\tau_{\mathrm{OH}}$ were set equal to $5 \times 10^{6}$ molecules $\mathrm{cm}^{-3}$ and $3 \mathrm{~h}$, respectively.

At present there is considerable uncertainty concerning the precursor emission rates and gas-phase reaction mechanisms that produce organic compounds having an extremely low saturation vapour pressure (Kesselmeier and Staudt, 1999; Bonn et al., 2002; Ziemann, 2002). However, we do not require exact knowledge of these mechanisms, since qualitative features related to the activation behaviour are independent of them. Therefore the production term of the organic vapour, $Q$, is modelled by assuming that it follows the time-development of $\mathrm{OH}$ radical, i.e. $Q=P_{\max } \exp \left[-\left(\left(t-t_{\max }\right) / \tau_{\text {prod }}\right)^{2}\right]$. The maximum production rate $P_{\max }$ is chosen so that the overall magnitude of $Q$ matches with estimates presented by Kulmala et al. (2001b) and Dal Maso et al. (2002). Furthermore, time when the pro- duction rate reaches its maximum, $t_{\max }$, and the production timescale, $\tau_{\text {prod }}$, are equal to $12: 00$ and $3 \mathrm{~h}$, unless otherwise mentioned.

\subsection{Treatment of the aerosol size distribution}

The pre-existing aerosol population is assumed to consist of two lognormal modes corresponding to the Aitken and accumulation mode. These particles are put into 40 equallyspaced size sections which span the diameter range 0.01$1 \mu \mathrm{m}$. The particle size and chemical composition are assumed to be uniform within each section. Under real atmospheric conditions, the particle size distribution is modified by condensation, coagulation, dilution and deposition processes. However, the size distribution of pre-existing particles was held fixed in all base case simulations, implying that pre-existing particles act as a sink to both condensable vapours and newly formed particles but do not grow to larger sizes. This assumption makes easier to analyse the results and show their most important features because the condensation sink CS in Eq. (2-4) is constant during the model run.

The time evolution of clusters and secondary particles that are formed during the model run are simulated using a separate grid which consists of 100 size sections. For the size distribution representation we chose a moving sectional technique because of its advantages in simulating condensation dominated problems (Zhang et al., 1999). In order to handle continuous nucleation in the moving-grid frame, the following approach is used: each simulation is divided into 100 time intervals corresponding to the number of size sections. After each time interval, all clusters nucleated during this time are put into a new size section, which then moves in size independent of other sections as a result of condensation and coagulation processes. The initial number of clusters in each section is therefore the nucleation rate times the length of the time interval. These clusters are assumed to have an initial diameter of $1 \mathrm{~nm}$ and to consist of ammonium bisulphate and water. Furthermore, the chemical composition and size of the clusters and subsequently formed particles is assumed to be uniform within each size section.

\subsection{Aerosol processes}

The nucleation rate, $J_{n u c}$, is treated in the model as a free parameter which stays constant during the model run. This approach was chosen because a more complex treatment, e.g. calculation of $J_{n u c}$ on the basis of some nucleation theory or its parameterization, would only mask the central features of the activation dynamics which are the main focus of this study.

Coagulation affects primarily nanometer-size clusters and particles rather than larger background particles (Wexler et al., 1994; Kerminen et al., 2001). Because pre-existing particles are described in the model using a separate grid, their self-coagulation could thus be neglected and only 
coagulation of newly formed clusters and particles was accounted for. The coagulation kernels were calculated using the Fuchs form of the Brownian coagulation coefficient (Seinfeld and Pandis, 1998).

The mass transfer of sulphuric acid and organic vapour between the gas phase and particles was simulated explicitly using the traditional condensation equation (Fuchs and Sutugin, 1971). The condensational fluxes of the vapours are driven by the difference $\left(C_{i}-C_{i, e q}\right)$, where $C_{i}$ is the gasphase concentration of the compound $i$ and $C_{i, e q}$ is its saturation vapour concentration over the particle surface. The magnitude of $C_{i, e q}$ for sulphuric acid was assumed to be negligible, i.e. it was set equal to zero. In the case of clusters and secondary particles, $C_{o s, e q}$ was calculated as described in Sect. 2.1. The saturation vapour concentration of the organic vapour as a pure compound, $C^{0}$, was set equal to $1 \times 10^{6}$ molecules $\mathrm{cm}^{-3}$. This value has been chosen according to estimates obtained from numerical simulations and empirical data (Kulmala et al., 1998; Kerminen et al., 2000). Finally, the mass accommodation coefficients and gas-phase diffusion coefficients were assumed to be equal to unity and $0.1 \mathrm{~cm}^{2} \mathrm{~s}^{-1}$, respectively, for both sulphuric acid and condensing organic vapour.

Equation (2) was derived assuming that $C_{o s, e q}$ is equal to zero over the surfaces of pre-existing particles. The validity of this approximation was tested by conducting a few model runs, in which $C_{o s, e q}$ over the pre-existing particles was calculated either by setting it equal to zero or calculating it explicitly. The obtained results differed only marginally (up to a few percent) from each other which validates the conducted approximation.

The gas-to-particle transfer of ambient water vapour was simulated assuming a thermodynamic equilibrium between the gas and particle phase. The particle water content was therefore calculated by solving Eq. (1), as described in Sect. 2.1.

\section{Model simulations}

The presentation of the simulation results is organized as follows. Section 4.1 is devoted to the most central features of the activation dynamics. Effects of a pre-existing particle population are subsequently discussed (Sect. 4.2), followed by a closer look at the influence of the nucleation rate (Sect. 4.3) and gas-phase chemistry (Sect. 4.4). The role of ambient conditions in activation dynamics is considered briefly in Sect. 4.5.

\subsection{General features of activation dynamics}

Figure 2 shows how the concentrations of the condensing vapours developed in time during the investigated model runs. In all these simulations, the values of the input parameters were chosen according to conditions typical for conti-

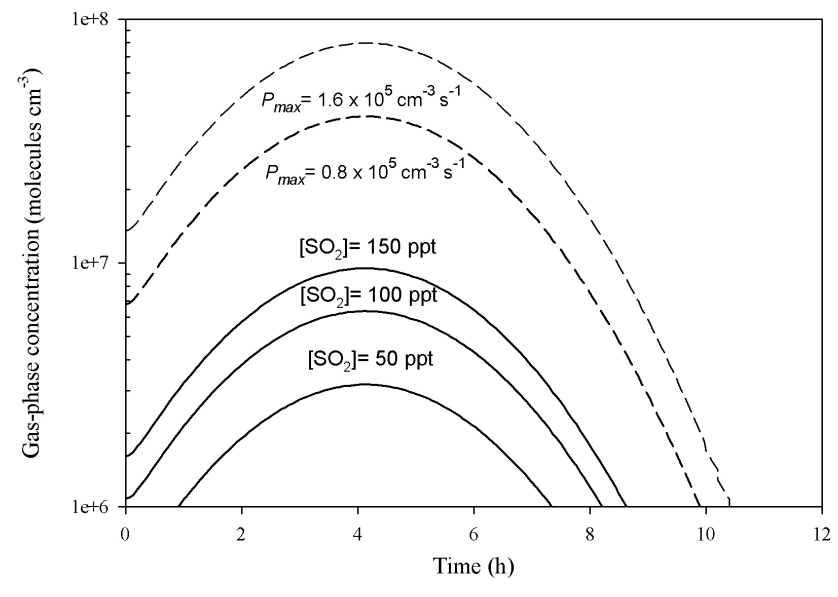

Fig. 2. Time evolution of the gas-phase concentration of sulphuric acid (solid lines) and organic vapour (dashed lines). The simulations start at 8:00 local time and end at 20:00 local time. The parameters $C S$ and $J_{n u c}$ were set equal to $2 \times 10^{-3} \mathrm{~s}^{-1}$ and $10 \mathrm{~cm}^{-3} \mathrm{~s}^{-1}$, respectively. The ambient temperature and relative humidity were assumed to be equal to $288 \mathrm{~K}$ and $80 \%$, respectively.

nental background areas (Weber et al., 1997; Birmili et al., 2000; Mäkelä et al., 2000; Kulmala et al., 2001b; Dal Maso et al., 2002). As can be seen, the gas-phase concentrations of sulphuric acid and organic vapour increased during the morning hours, reached their maximum at noon and began to decrease in the afternoon. In the case sulphuric acid, the simulated gas-phase concentrations are consistent with ambient measurements (Weber et al., 1997; Birmili et al., 2000) and, in the case of the organic vapour, with indirect estimates based on observed particle growth rates (Kulmala et al., 2001b; Dal Maso et al., 2002). These concentrations were also compared with the respective steady-state values. A close agreement between these two quantities was found, which demonstrates that Eq. (4) gives a good approximation to the saturation ratio of the condensing organic vapour.

The activation behaviour of clusters is illustrated in Fig. 3 which depicts the time development of the diameter and number concentration of clusters and newly formed particles in a few selected size sections. The first size section contains clusters which were formed at 8:00 local time, i.e. at the beginning of the model run. Practically all of these clusters coagulated away before reaching larger sizes due to low concentrations of condensable vapours at that time. In contrast, clusters formed at around 11:00 local time grew sufficiently fast to overcome complete coagulational scavenging and therefore a fraction of them survived throughout the simulation. As can be seen, the cluster growth rate was considerably enhanced after the clusters reached sizes of around $2 \mathrm{~nm}$ in diameter. This is due activation of the clusters with respect to organic vapour that condensed spontaneously onto the clusters and thereby grew them effectively into detectable sizes. However, the growth slowed down in 


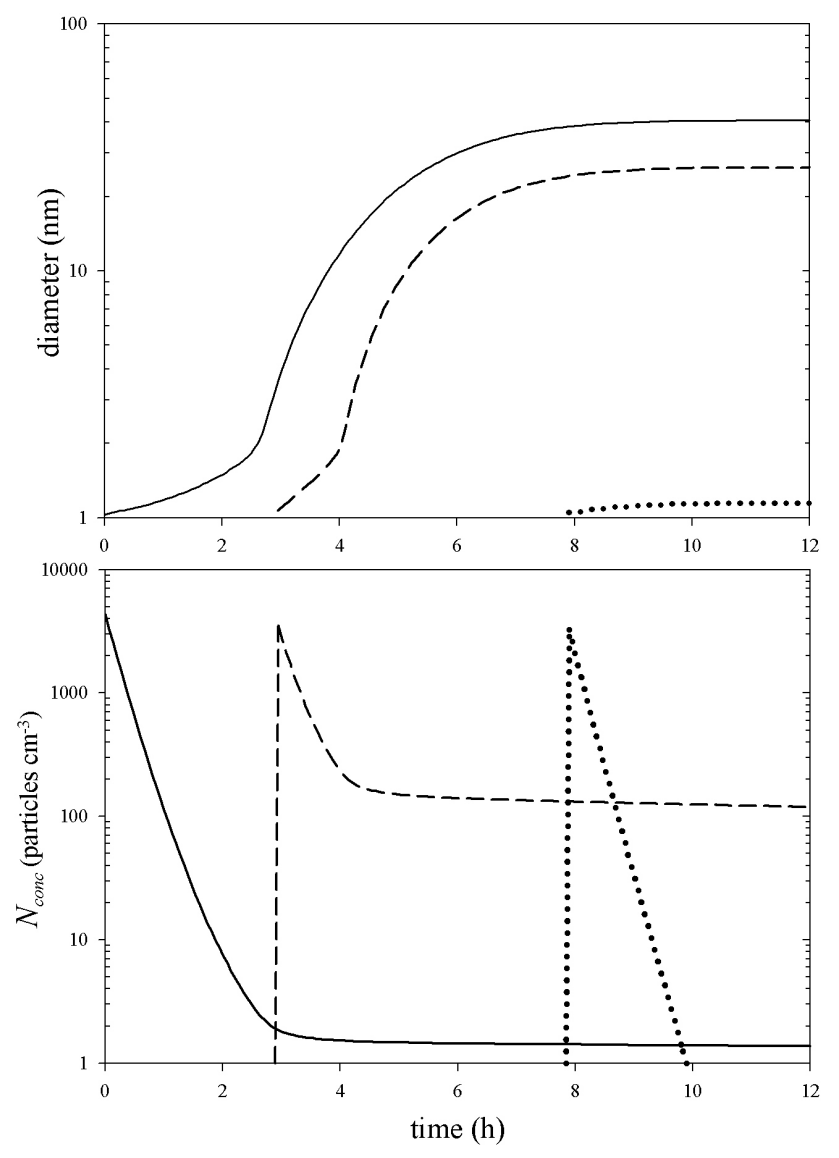

Fig. 3. The time evolution of the diameter (top) and number concentration (bottom) of clusters and newly formed particles that are nucleated at the beginning of the simulation, i.e. at 8:00 local time (solid lines), around 11:00 local time (dashed lines) and around 16:00 local time (dotted lines). The parameters $P_{\max }$ and $\left[\mathrm{SO}_{2}\right]$ were chosen to be equal to $1.6 \times 10^{5} \mathrm{~cm}^{-3} \mathrm{~s}^{-1}$ and $150 \mathrm{ppt}$, respectively. The values of the other input parameters were chosen as in Fig. 2.

the afternoon because the gas-phase concentrations of the condensing vapours began to decrease at noon. This also explains why the clusters that were formed in the evening or late afternoon experienced the same fate as those formed in the early morning, i.e. they were rapidly scavenged away by larger particles.

Figure 4 shows the size distribution of nucleated clusters and subsequently formed particles in the same model run at four different local times. The first size distribution is at three hours from the start of the simulation, i.e. at 11:00 local time. At this stage some of the clusters had already activated and grown to detectable sizes. A distinguishable nucleation mode had been formed one hour later and the largest newly formed particles had reached sizes of around $10 \mathrm{~nm}$ in diameter. Assuming that these particles had been nucleated in the beginning of the simulation, it can be inferred that their growth rate was around $2 \mathrm{~nm} / \mathrm{h}$. This estimate is consistent with observed particle growth rates in remote continental sites (e.g. Birmili et al., 2000; Mäkelä et al., 2000). The particle formation and growth continued a few hours after midday, but eventually the gas-phase concentrations of the condensing vapours decreased to such low levels that they could not sustain a significant particle growth. Together with rapid coagulational scavenging this led to a decrease in the number concentrations of clusters and particles having diameter between 1 and $5 \mathrm{~nm}$. As seen from the last two size distributions, corresponding to 14:00 and 20:00 local time, respectively, the formation of the resulting "gap" began in the afternoon and has clearly formed by the evening.

Figure 5 shows the time evolution of the total number concentration and mean diameter of newly formed particles. The significance of sulphuric acid to the particle formation is evident. When the maximum gas-phase concentration of sulphuric acid was $<3 \times 10^{6}$ molecules $\mathrm{cm}^{-3}$ (Fig. 2), the clusters grew slowly and were scavenged by larger particles before reaching activation sizes. As a result no particle formation took place in these simulations. However, when the maximum concentration of sulphuric acid was $>5 \times 10^{6}$ molecules $\mathrm{cm}^{-3}$ and the value of $P_{\max }$ was around $10^{5}$ molecules $\mathrm{cm}^{-3} \mathrm{~s}^{-1}$, freshly-nucleated clusters grew rapidly to activation sizes. In these cases, the appearance of particles having a diameter $>3 \mathrm{~nm}$ can be seen after $2-4 \mathrm{~h}$ from the start of the model run, i.e. between 10:00 and 12:00 local time. The number concentration of secondary particles rose rapidly until the early afternoon after which it began to decrease due to coagulation. The mean diameter of the newly formed particles increased until the late afternoon when it reached values between 10 and $20 \mathrm{~nm}$.

Sulphuric acid was not able to induce a significant particle formation alone unless its maximum gas-phase concentration was $>10^{7}$ molecules $\mathrm{cm}^{-3}$. This was seen by conducting model runs, in which the production rate of the organic vapour was set equal to zero. In these simulations, the gas-phase concentration of sulphuric acid had to reach values of around $5 \times 10^{7}$ molecules $\mathrm{cm}^{-3}$ before particles having a diameter $>10 \mathrm{~nm}$ were formed in noticeable amounts. Otherwise a clear majority of newly formed particles remained in the size range $<10 \mathrm{~nm}$.

\subsection{Effects of a pre-existing particle population}

Pre-existing particles affect the activation dynamics in two ways: they act as a sink for condensable vapours (Eq. 4) and reduce the number of clusters and newly formed particles via coagulational scavenging. The parameter $C S$ provides a suitable measure for both of these effects and therefore we investigated more closely this issue by performing a set of model runs in which the value of $C S$ was varied (Table 1).

An apparent feature seen from the simulation results is that particle formation is highly sensitive to the value of $C S$, such that the number of newly formed particles decreases rapidly as the value of $C S$ increases. This effect is somewhat 

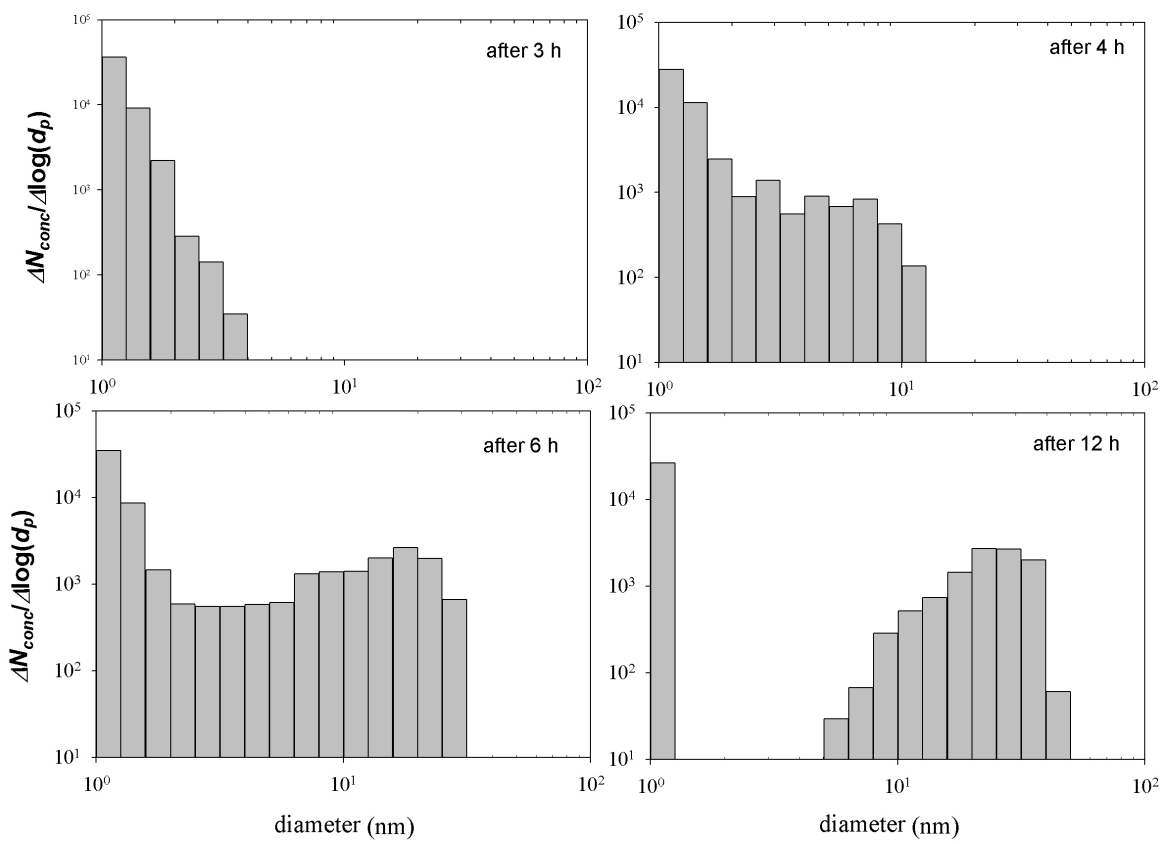

Fig. 4. The size distribution of nucleated clusters and newly-particles in the same model run at four different local times. The values of the input parameters were chosen as in Fig. 3. The figures were obtained by distributing newly formed clusters and particles into twenty different size classes.
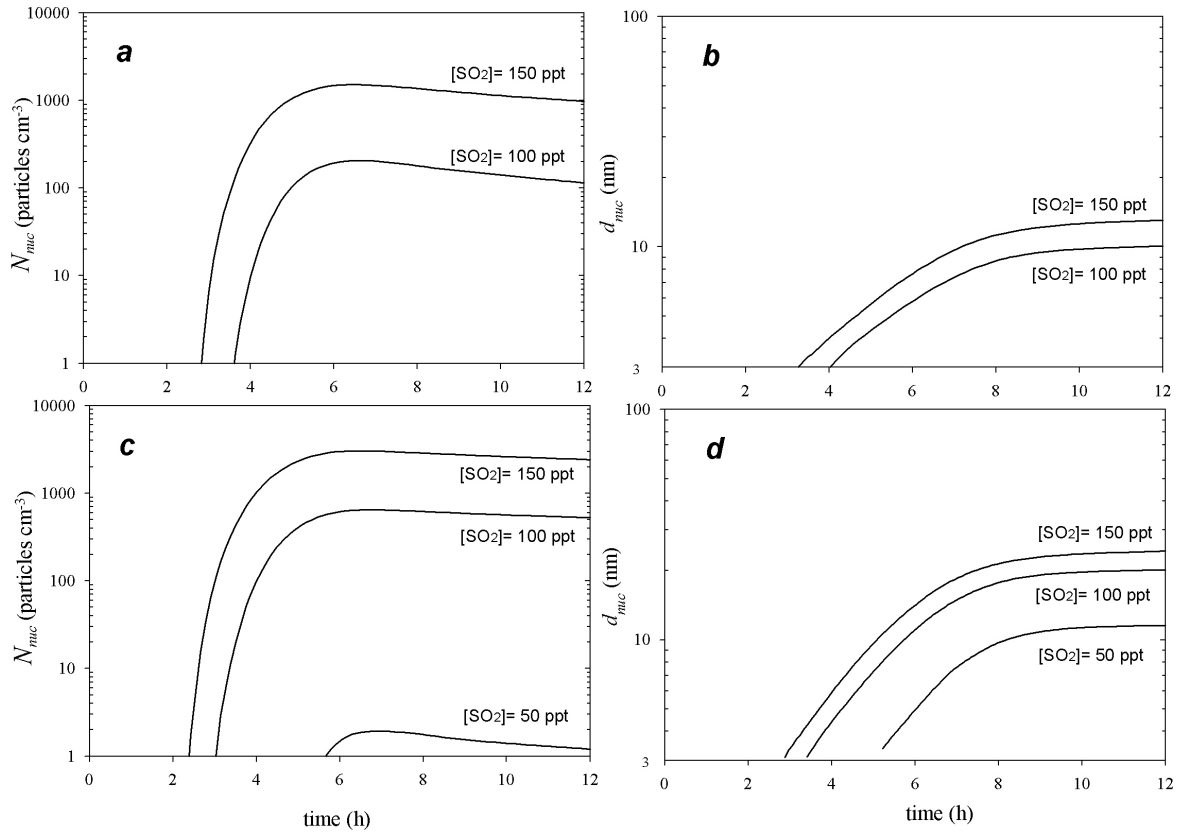

Fig. 5. Time evolution of the number concentration of detectable $(>3 \mathrm{~nm})$ secondary particles $N_{n u c}(\mathrm{a}$ and c) and the mean diameter of the particles $d_{n u c}$ (b and d). The parameter $P_{\max }$ was set equal to $1.6 \times 10^{5} \mathrm{~cm}^{-3} \mathrm{~s}^{-1}$ (bottom) and $8 \times 10^{4} \mathrm{~cm}^{-3} \mathrm{~s}^{-1}$ (top). The values of the other input parameters were chosen as in Fig. 3.

compensated by increased production rates of sulphuric acid and organic vapour. However, even if their production terms are increased in such a way that their gas-phase concentra- tions stay about the same, the number of nucleation mode particles decreases as the value of $C S$ increases because freshly-formed clusters are scavenged away more rapidly. 
Table 1. Maximum gas-phase concentrations of sulphuric acid and the condensing organic vapour, $\left[\mathrm{H}_{2} \mathrm{SO}_{4}\right](\max )$ and $C_{o s}(\max )$, respectively, during the 12-hour simulations. The maximum number concentration of newly formed particles, $N_{\text {nuc }}$ (max), and their maximum mean diameter, $d_{n u c}(\max )$, are also shown. The chosen value range of $C S$ reflects conditions typical for continental background areas (Kulmala et al., 2001b; Dal Maso et al., 2002). The values of the other input parameters were chosen as in Fig. 2.

\begin{tabular}{|c|c|c|c|c|c|}
\hline$P_{\max }, \times 10^{5} \mathrm{~cm}^{-3} \mathrm{~s}^{-1}$ & {$\left[\mathrm{SO}_{2}\right], \mathrm{ppt}$} & {$\left[\mathrm{H}_{2} \mathrm{SO}_{4}\right](\max ), \times 10^{6} \mathrm{~cm}^{-3}$} & $C_{o s}(\max ), \times 10^{7} \mathrm{~cm}^{-3}$ & $N_{n u c}(\max ), \mathrm{cm}^{-3}$ & $d_{n u c}(\max ), \mathrm{nm}$ \\
\hline \multicolumn{6}{|c|}{$C S=2 \times 10^{-3} \mathrm{~s}^{-1}$} \\
\hline 1.2 & 150 & 9.5 & 6.0 & 2400 & 19 \\
\hline 2.5 & 150 & 9.4 & 12 & 4200 & 37 \\
\hline 2.5 & 300 & 17 & 11 & 12000 & 43 \\
\hline 3.75 & 450 & 22 & 15 & 15000 & 58 \\
\hline \multicolumn{6}{|c|}{$C S=4 \times 10^{-3} \mathrm{~s}^{-1}$} \\
\hline 1.2 & 450 & 14 & 3.0 & 220 & 13 \\
\hline 2.5 & 300 & 9.5 & 6.2 & 63 & 18 \\
\hline 2.5 & 450 & 14 & 6.2 & 580 & 22 \\
\hline 3.75 & 150 & 4.8 & 9.4 & 0 & - \\
\hline 3.75 & 450 & 14 & 9.3 & 1000 & 31 \\
\hline 5.0 & 600 & 19 & 12 & 3300 & 45 \\
\hline \multicolumn{6}{|c|}{$C S=6 \times 10^{-3} \mathrm{~s}^{-1}$} \\
\hline 2.5 & 300 & 6.4 & 4.2 & 0 & - \\
\hline 2.5 & 600 & 13 & 4.2 & 9 & 15 \\
\hline 3.75 & 450 & 9.5 & 6.2 & 2 & 15 \\
\hline 5.0 & 150 & 3.2 & 8.3 & 0 & - \\
\hline 5.0 & 600 & 13 & 8.3 & 38 & 26 \\
\hline
\end{tabular}

On the other hand, if the production terms do not increase in pace with $C S$, the gas-phase concentrations of condensing vapours might decrease to such an extent that the particle formation is completely suppressed.

The size distribution of background particles has been fixed in the simulations considered so far. For comparison, we performed several model runs in which the size distribution of pre-existing particles was allowed to move as a response to condensation and coagulation processes. These model runs revealed that condensation of sulphuric acid and organic vapour onto pre-existing particles increases the value of $C S$ and consequently the number of newly formed particles decreases. However, the general features of the activation dynamics, which are our principal interest in this paper, remain the same. In addition, some processes neglected here, such as deposition and dilution, decrease the value of $C S$ in the real atmosphere and therefore these sensitivity studies do not necessarily lead to more realistic particle formation rates than those in the base case simulations.

\subsection{Cluster growth by self coagulation}

The model runs presented in Sect. 4.1 demonstrated that freshly-nucleated clusters have to reach a diameter of around $2 \mathrm{~nm}$ before they can activate with respect to a low-volatile organic vapour. In addition, it was concluded that sulphuric acid is able to grow clusters effectively into this threshold size under conditions typical for continental background areas. Another mechanism which may grow freshly-nucleated clusters effectively is their self coagulation. Because the re- sulting growth rate is dependent on the cluster number concentration, we addressed this issue by conducting a number of simulations in which the nucleation rate, $J_{\text {nuc }}$, was varied (Table 2).

From Table 2 can be seen that the magnitude of $J_{\text {nuc }}$ must be order of $10^{3} \mathrm{~cm}^{-3} \mathrm{~s}^{-1}$ or greater for the clusters to grow via self coagulation so rapidly that significant particle formation results. The required magnitude of $J_{n u c}$ depends strongly on a pre-existing particle population. For example, $J_{\text {nuc }}$ had to be increased from $\sim 10^{3}$ to $\sim 5 \times 10^{3} \mathrm{~cm}^{-3} \mathrm{~s}^{-1}$ when the value of $C S$ was increased from $2 \times 10^{-3}$ to $4 \times 10^{-3} \mathrm{~s}^{-1}$ to sustain a notable particle formation.

In order to find out whether self coagulation has an importance to the cluster growth under real atmospheric conditions, we compared the magnitude of $J_{n u c}$ estimated above with the estimated nucleation rates in a continental background site (Kulmala et al., 2001b; Dal Maso et al., 2002). These studies indicate that stable clusters having a diameter $1 \mathrm{~nm}$ are formed at rates ranging from 10 to $100 \mathrm{~cm}^{-3} \mathrm{~s}^{-1}$. Accordingly, self coagulation is expected to be of secondary importance when considering the initial stages of cluster growth in continental background areas. This conclusion does not, however, necessarily hold in coastal areas where the estimated cluster formation rates may exceed those in continental background areas by several orders of magnitude (O’Dowd et al., 1998). Furthermore, it should be noted that self-coagulation decreases the cluster number concentration significantly. For example, if clusters grow from 1 to $3 \mathrm{~nm}$ in diameter via self-coagulation, their number concentration is reduced by a factor of 27 . 
Table 2. The maximum number concentration of newly formed particles, $N_{n u c}$ (max), and their maximum mean diameter, $d_{n u c}$ (max), during the 12-hour simulations. No gaseous sulphuric acid were assumed to be present. The values of the other input parameters were chosen as in Fig. 2.

\begin{tabular}{cccc}
\hline$J_{\text {nuc }} \mathrm{cm}^{-3} \mathrm{~s}^{-1}$ & $P_{\text {max }} \times 10^{5} \mathrm{~cm}^{-3} \mathrm{~s}^{-1}$ & $N_{\text {nuc }}(\max ) \mathrm{cm}^{-3}$ & $d_{\text {nuc }}(\max ) \mathrm{nm}$ \\
\hline \multicolumn{4}{c}{$C S=2 \times 10^{-3} \mathrm{~s}^{-1}$} \\
500 & 0.8 & 6 & 9 \\
750 & 0.8 & $2.4 \times 10^{3}$ & 12 \\
$10^{3}$ & 0.8 & $1.2 \times 10^{4}$ & 15 \\
100 & 1.2 & 0 & - \\
500 & 1.2 & 250 & 15 \\
$10^{3}$ & 1.2 & $1.8 \times 10^{5}$ & 23 \\
\multicolumn{4}{c}{$C S=4 \times 10^{-3} \mathrm{~s}^{-1}$} \\
$2.5 \times 10^{3}$ & 2.5 & $4.4 \times 10^{3}$ & 24 \\
$5 \times 10^{3}$ & 2.5 & $5.7 \times 10^{4}$ & 34 \\
$10^{4}$ & 2.5 & $1.7 \times 10^{5}$ & 43 \\
$10^{3}$ & 3.75 & 1 & 4 \\
$2.5 \times 10^{3}$ & 3.75 & $8.9 \times 10^{3}$ & 36 \\
$5 \times 10^{3}$ & 3.75 & $7.0 \times 10^{4}$ & 44 \\
$10^{4}$ & 3.75 & $1.5 \times 10^{6}$ & 88 \\
\hline
\end{tabular}

\subsection{Effects of gas-phase chemistry}

As described in Sect. 3.1, the production rate of a condensing organic vapour, $P_{\max }$, was modelled assuming that it follows closely the gas-phase concentration of the $\mathrm{OH}$ radical. This is a reasonable choice because the $\mathrm{OH}$ radical reacts rapidly with many volatile organic compounds (VOCs) which are principal precursors for condensable organic vapours in the atmosphere (Kesselmeir and Staudt, 1999). The initial oxidation of VOCs is followed by a complex reaction sequence, during which reaction products get increasingly oxidized, containing thereby more functional groups (e.g. Jenkins et al., 2000; Peeters et al., 2001). Since the presence of multiple functional groups tend to make a compound less volatile, the condensable organic vapour might be formed only after multiple oxidative reactions. This means that $P_{\max }$ may reach its maximum value later than the gas-phase concentration of the $\mathrm{OH}$ radical, in contrast to what was assumed in the base case simulations.

The sensitivity of the new particle formation to the time when $P_{\max }$ reaches its maximum, $t_{\max }$, was investigated and the results are shown in Table 3. As can be seen, optimal conditions for new particle formation are reached when the organic vapour concentration has its maximum approximately one hour later than sulphuric acid, i.e. at 13:00 local time. When the time lag increases, a larger fraction of freshlynucleated clusters coagulate away before reaching activation sizes, since the gas-phase concentration of sulphuric acid has already decreased significantly when the organic vapour is at its peak concentration. Therefore the number of newlyformed particles decreases when the time lag increases above two hours.

\subsection{Effects of ambient conditions}

The temperature $(T)$ and relative humidity $(R H)$ were held constant in all model runs presented so far. Furthermore, the influences of meteorological processes on the concentration levels of particles and condensing vapours were not accounted for, even though all these quantities exhibit both temporal and spatial variations due to changes in atmospheric conditions. The effects of these variations on particle formation cannot be fully explored, since our current understanding of several key processes, such as the gas-phase chemistry and nucleation, is far from complete. Here we focus on those effects that can be quantified using the developed numerical model and simple theoretical considerations. In particular, we do not investigate whether concentration fluctuations are able to enhance cluster activation (in a case of cloud droplet activation this has been suggested to occur, see Kulmala et al., 1997).

Changes in the temperature affect primarily the saturation ratio of the organic vapour, $S_{o s}$, due to the exponential temperature dependence of the saturation vapour pressure. Since the particle formation typically begins in the morning, it is worthwhile to consider whether the temperature changes at that time of day could affect the time development of $S_{o s}$. In order to estimate the magnitude of this effect, we applied the Clausius-Clapeyron equation in (3) and obtained:

$\frac{d S_{o s}}{d t}=\frac{Q}{C_{0}}-S_{o s} \times\left(C S+\frac{\Delta H_{o s}}{R \times T^{2}} \times \frac{d T}{d t}\right)$.

Here $\Delta H_{O S}\left(\mathrm{~J} \mathrm{~mol}^{-1}\right)$ is the enthalpy of vaporization and $R$ is the universal gas constant. The last term in parenthesis in the right-hand side of (5) contains the temperature dependence of 
Table 3. The maximum number concentration of formed particles, $N_{n u c}$ (max), and their maximum mean diameter, $d_{n u c}$ (max), during the 12-hour simulations. The chosen values of $\left[\mathrm{SO}_{2}\right], P_{\max }$ and $t_{\max }$ are also shown. The values of the other input parameters were chosen as in Fig. 2. Simulations with $t_{\max }$ equal to 12:00 are the base case simulations.

\begin{tabular}{|c|c|c|c|}
\hline$\left[\mathrm{SO}_{2}\right], \mathrm{ppt}$ & $P_{\max } \times 10^{5} \mathrm{~cm}^{-3} \mathrm{~s}^{-1}$ & $N_{n u c}(\max ) \mathrm{cm}^{-3}$ & $d_{n u c}(\max ) \mathrm{nm}$ \\
\hline \multicolumn{4}{|c|}{$t_{\max }=12: 00$} \\
\hline 150 & 0.8 & $1.5 \times 10^{3}$ & 13 \\
\hline 100 & 0.8 & 210 & 10 \\
\hline 150 & 1.6 & $3.0 \times 10^{3}$ & 24 \\
\hline 100 & 1.6 & 640 & 20 \\
\hline \multicolumn{4}{|c|}{$t_{\max }=13: 00$} \\
\hline 150 & 0.8 & $1.6 \times 10^{3}$ & 15 \\
\hline 100 & 0.8 & 250 & 12 \\
\hline 150 & 1.6 & $3.1 \times 10^{3}$ & 28 \\
\hline 100 & 1.6 & 740 & 22 \\
\hline \multicolumn{4}{|c|}{$t_{\max }=14: 00$} \\
\hline 150 & 0.8 & $1.5 \times 10^{3}$ & 17 \\
\hline 100 & 0.8 & 240 & 14 \\
\hline 150 & 1.6 & $2.8 \times 10^{3}$ & 32 \\
\hline 100 & 1.6 & 640 & 30 \\
\hline \multicolumn{4}{|c|}{$t_{\max }=16: 00$} \\
\hline 150 & 0.8 & 830 & 17 \\
\hline 100 & 0.8 & 120 & 15 \\
\hline 150 & 1.6 & $1.5 \times 10^{3}$ & 33 \\
\hline 100 & 1.6 & 290 & 31 \\
\hline
\end{tabular}

$S_{o s}$. The relative importance of this term can be estimated by comparing its magnitude with that of $C S$. The enthalpies of vapourization for atmospheric organic compounds are typically $<170 \mathrm{~kJ} \mathrm{~mol}^{-1}$ (Strader et al., 1999; Sheehan and Bowman, 2002) and the temperature changes probably no faster than a few Kelvin degrees per hour. The value of the considered term is thus $<10^{-4} \mathrm{~s}^{-1}$ in the temperature range $>273 \mathrm{~K}$. Since the value of $C S$ is $>10^{-3} \mathrm{~s}^{-1}$ at continental boundary layers, it can be concluded that diurnal variation of the temperature has only a minor effect on the time development of $S_{o s}$ and, consequently, to particle formation taking place at continental areas.

An air parcel where the particle formation takes place may experience convective updrafts that cause a rapid cooling of the parcel. The influence of this process to the time development of $S_{o s}$ can be estimated using (5). In the case of adiabatic cooling the maximum temperature change is given by the dry adiabatic lapse rate which is equal to $-9.8 \mathrm{~K} \mathrm{~km}^{-1}$ (e.g. Seinfeld and Pandis, 1998). Assuming further that the vapourization enthalpy of the organic vapour and updraft velocity are equal to $170 \mathrm{~J} \mathrm{~mol}^{-1}$ and $1 \mathrm{~m} \mathrm{~s}^{-1}$ (which are upper limit estimates for these parameters) respectively, a value of around $10^{-3} \mathrm{~s}^{-1}$ for the last term in the parenthesis in the right hand side of (5) is obtained. This value is of the same magnitude than that of $C S$. Therefore the effect of adiabatic cooling on the time development of $S_{\text {os }}$ may be comparable to that of the condensation under such conditions, demonstrating the potential importance of meteorological processes to the activation behaviour.
In the developed model the relative humidity affects primarily the water uptake of clusters and larger particles. The pre-existing particle population absorbs more water as $R H$ increases and they become consequently a larger sink for condensing vapours, newly formed particles and clusters. Correspondingly, the value of $C S$ is decreases with decreasing $R H$. With an aid of our model, we calculated that the value of $C S$ may change up to a factor of two as $R H$ varies in the range $60-90 \%$. The chemical composition of freshlyformed clusters depends also on $R H$, such that their activation is favoured at higher relative humidities. However, the model runs in which the relative humidity was varied indicated that this effect is dominated by the variation of $C S$ with $R H$.

Finally, we investigated how diurnal variations in the atmospheric mixed layer height influences the particle formation. The considered time of day was the morning, during which the height of the mixed layer typically grows rapidly as a response to the solar heating. The associated dilution of mixed layer air decreased the number concentration of preexisting particles, thereby alleviating new particle formation. The growth of the mixed layer height was modelled by forcing the value of $C S$ along with the concentrations of clusters and newly formed particles to decrease linearly a few hours starting at 9:00 local time. The duration and magnitude of the decrease were chosen according to Nilsson et al. (2001) and Dal Maso et al. (2002). Performed model runs demonstrated that the mixed layer growth may reduce the pre-existing particle concentrations in such a way that it 
triggers new particle formation. For example, during a model run in which the value of $C S$ decreased from $4 \times 10^{-3} \mathrm{~s}^{-1}$ to around $2.5 \times 10^{-3} \mathrm{~s}^{-1}$ in three hours, the number of newly formed particles reached values of around $1.2 \times 10^{3} \mathrm{~cm}^{-3}$. In contrast, no particle formation did take place when the value of $C S$ was kept equal to $4 \times 10^{-3} \mathrm{~s}^{-1}$ throughout the model run.

\section{Seasonal variation of aerosol formation events}

Organic vapours that may become sufficiently supersaturated to cause the activation of freshly-nucleated clusters in the atmosphere have probably a very low saturation concentration as a pure compound, i.e. $<10^{6}-10^{7}$ molecules $\mathrm{cm}^{-3}$ (Kulmala et al., 1998; Kerminen et al., 2000; Anttila and Kerminen, 2003). Although there has been some progress in understanding the chemical mechanisms that might produce such compounds in the atmosphere (Tobias and Ziemann, 2000; Tobias et al., 2000; Bonn et al., 2002; Ziemann, 2002), their identity and exact physico-chemical properties remain still unclear. This is one of the major reasons why the results obtained in this study cannot be properly tested against experimental data. However, they are consistent with many features related to aerosol formation events taking place at continental areas.

A five-year-long data set on observed particle formation events at a continental forest site in Finland displays a strong seasonal variation in the number of occurrence of these events, with a maximum during the spring and a minimum in summer (Kulmala et al., 2001a). The processes investigated in the present paper (formation of inorganic clusters by nucleation, their initial growth by sulphuric acid, and their activation by organic vapours) can explain this feature. Using the measured UV radiation and $\mathrm{SO}_{2}$ concentration data, as well as data on calculated condensation sinks, the estimated sulphuric acid concentration at the site is on average three times higher in spring than in summer. The results presented in Sect. 4.3 suggest that the growth of non-activated clusters is driven by condensation of sulphuric acid under conditions typical for the measurement site. The resulting growth rate is directly proportional to the gas-phase concentration of sulphuric acid (e.g. Weber et al., 1997) and non-activated clusters are thus expected to grow about three times more rapidly in springtime than in summer. In addition, the average saturation vapour pressure of organic vapours (estimated using observed temperature data and a typical temperature dependence of $C^{0}$ for organic vapours) is roughly a factor four smaller in spring than in summer, implying that considerably smaller organic vapour concentrations are required for cluster activation in spring. These two things explain together the basic physics behind why we have more particle formation events in spring than in summer. In addition, the observed growth rates of newly formed particles are 3-4 times higher in summer than in spring. This is also consistent with our results, because at the summertime the growth rates should be significantly higher due to the higher organic vapour concentrations needed to reach a certain value of $S_{o s}$.

\section{Summary and conclusions}

We have applied a framework describing activation of freshly-nucleated inorganic clusters by a supersaturated organic vapour to explain how organic particles are formed in the atmosphere. Nanometer-size clusters were shown to activate, i.e. begin to grow by spontaneous condensation of a water-soluble organic vapour, after reaching a certain threshold size. The onset of the activation is determined both by the Kelvin and solvent/solute effects, which were treated using a detailed thermodynamical model. In order to investigate the resulting particle formation, the applied framework was coupled to a box-model simulating the appropriate aerosol and gas-phase processes.

The activation behaviour of nanometer-size clusters was shown to differ considerably from the cloud droplet activation described by the traditional application of the Köhler theory. First, newly formed clusters and particles do not limit the activation process by scavenging the available condensing vapour. In contrast, the concentration of the condensing organic vapour is determined by the relative magnitudes of its production rate and loss rate to a pre-existing particle population. Because of this, the supersaturation of the condensing organic vapour may reach values $10-1000$ over a timescale of a few hours. This should be contrasted with the cloud formation, during which water vapour reaches typically supersaturations of around $0.1 \%$ at maximum over a timescale of minutes due to a rapid depletion of water vapour onto growing cloud droplets.

The performed simulations indicated that the growth of freshly-nucleated clusters and subsequently formed organic particles is driven by condensation of both sulphuric acid and organic vapour. Sulphuric acid is responsible for the initial growth of the clusters to sizes of around $2 \mathrm{~nm}$ in diameter. Once the clusters have reached this threshold size, they become activated by the organic vapour. Under favourable conditions, this is followed by a rapid growth so that a distinguishable particle formation event takes place.

Self coagulation may provide an alternative pathway for the cluster growth in the absence of sufficient amounts of gaseous sulphuric acid. The conducted simulations revealed that this mechanism is effective only when the nucleation rate is $>10^{3}$ molecules $\mathrm{cm}^{-3} \mathrm{~s}^{-1}$. Whether such high nucleation rates take place at continental boundary layers cannot be conclusively assessed at present. However, indirect evidence obtained from field measurements carried out in a remote continental site indicate that the actual nucleation rates might be lower than this value by an order of magnitude or more (Kulmala et al., 2001b; Dal Maso et al., 2002). This implies that condensation of sulphuric acid is a more viable mechanism 
for the initial growth of nucleated clusters than their mutual coagulation.

The model runs demonstrated that a shortage of either gaseous sulphuric acid or condensing organic vapours limits, or even suppresses altogether, the organic particle formation. In a case where sulphuric acid has a sufficiently low gas-phase concentration, i.e. below the order of $10^{6}$ molecules $\mathrm{cm}^{-3}$, nucleated clusters do not reach sizes in which they able to activate but are rapidly removed from the atmosphere by coagulational scavenging. On the other hand, organic vapours are required to grow nanometer-size clusters and particles effectively into nucleation mode sizes unless sulphuric acid has gas-phase concentration $>10^{7}$ molecules $\mathrm{cm}^{-3}$.

The conducted simulations along with theoretical considerations revealed also that meteorological processes such as dilution and adiabatic cooling of the air masses may influence cluster activation considerably. The former process decreases the surface area of a pre-existing particle population, whereas the latter process decreases the saturation vapour pressure of the organic compound. Both these processes increase the saturation ratio of the organic compound and alleviate thereby cluster activation. These findings are also consistent with the empirical study of Nilsson et al. (2001) which demonstrates the importance of meteorological processes to aerosol formation at continental boundary layers.

Since organic vapours responsible for particle formation in the atmosphere remain to be identified, their exact physicochemical properties are largely unknown. Because of this, we had to apply indirect experimental data when modelling the interactions between a condensing organic vapour and nanometer-size inorganic clusters. Due to the robustness of the applied framework, however, the associated uncertainties do not affect the overall picture on organic particle formation that the present study provides. As more relevant experimental data is obtained, it can be utilized to improve the accuracy of the developed approach. Additionally, numerical models incorporating the applied theory can be extended in future to account for the processes that are not covered by the model applied here.

Acknowledgements. This work was supported by the Maj and Tor Nessling Foundation. Dr. K. E. J. Lehtinen (University of Helsinki) is acknowledged for his helpful comments.

Edited by: K. Carslaw

\section{References}

Alvarez, E., Vazquez, G., Sanchez-Vilas, M., Sanjurjo, B., and Navaza, J. M.: Surface tension of organic acids + water binary mixtures from $20^{\circ} \mathrm{C}$ to $50^{\circ} \mathrm{C}$, J. Chem. Eng. Data, 42, 957-960, 1997.

Anttila. T. and Kerminen, V.-M.: Condensational growth of atmospheric nuclei by organic vapours, J. Aerosol Sci., 34, 41-61, 2003.
Birmili, W., Wiedensohler, A., Plass-Dülmer, C., and Berresheim, H.: Evolution of newly formed aerosol particles in the continental boundary layer: A case study including $\mathrm{OH}$ and $\mathrm{H}_{2} \mathrm{SO}_{4}$ measurements, Geophys. Res. Lett., 27, 2205-2208, 2000.

Bonn, B., Schuster, G., and Moortgat, G. K.: Influence of water vapour on the process of new particle formation during monoterpene ozonolysis, J. Phys. Chem. A, 106, 2869-2881, 2002.

Bonn, B. and Moortgat, G. K.: Sesquiterpene ozonolysis: Origin of atmospheric new particle formation from biogenic hydrocarbons, Geophys. Res. Letts., 30, doi:10.1029/2003GL017000, 2003.

Clarke, A. D.: Atmospheric nuclei in the remote free-troposphere, J. Atmos. Chem., 14, 479-488, 1992.

Covert, D. S., Kapustin, V. N., Quinn, P. K., and Bates, T. S.: New particle formation in the marine boundary layer, J. Geophys. Res., 97, 20 581-26 905, 1992.

Dal Maso, M., Kulmala, M., Lehtinen, K. E. J., Mäkelä, J. M., Aalto, P. and O'Dowd, C. D.: Condensation and coagulation sinks and formation of nucleation mode particles in coastal and boreal forest boundary layers, J. Geophys. Res., 107, doi:10.1029/2001JD001053, 2002.

Fuchs, N. A. and Sutugin, A. G.: Highly Dispersed Aerosols, Butteworth-Heinemann, Newton Mass., 1970.

Gao, S., Hegg, D. A., Frick, G., Caffrey, P. F., Pasternack, L., Cantrell, C., Sullivan, W., Ambrusko, J., Albrechcinski, T., and Kirchstetter, T. W.: Experimental and modelling studies of secondary organic aerosol formation and some applications to the marine boundary layer, J. Geophys. Res., 106, 27 619-27 634, 2001.

Hämeri, K. and Väkevä, M.: Ultrafine aerosol particle hygroscopicity and volatility in boreal forest, Rep. Ser. Aerosol Sci., 47, 47-59, 2000

Hämeri, K., Väkevä, M., Aalto, P., Kulmala, M., Swietlicki, E., Zhou. J., Seidl, W., Becker, E., and O'Dowd, C. D.: Hygroscopic and $\mathrm{CCN}$ properties of aerosol particles in boreal forest, Tellus, 53B, 359-379, 2001.

IPCC (2001): Climate Change 2001, The Scientific Basis, Cambridge University Press, Cambridge, 2001.

Jenkin, M. E., Shallcross, D. E., and Harvey, J. N.: Development and application of a possible mechanism for the generation of cis-pinic acid from the ozonolysis of $\alpha$ - and $\beta$-pinene, Atmos. Env., 34, 2837-2850, 2000.

Kavouras, I. G., Mihalopoulos, N., Stephanou, E. G.: Formation of atmospheric particles from organic acids produced by forests, Nature, 395, 683-686, 1998.

Kerminen, V.-M., Virkkula, A., Hillamo, R., Wexler, A. S., and Kulmala, M.: Secondary organics and atmospheric cloud condensation nuclei production. J. Geophys. Res., 105, 9255-9264, 2000.

Kerminen, V.-M., Pirjola, L., and Kulmala, M.: How significantly does coagulational scavenging limit atmospheric particle production?, J. Geophys. Res., 106, 24 119-24 125, 2001.

Kerminen, V.-M. and Kulmala, M.: Analytical formulae connecting the "real" and "apparent" nucleation rate and the nuclei number concentration for atmospheric nucleation events, J. Aerosol Sci., 33, 609-623, 2002.

Kesselmeier, J. and Staudt, M.: Biogenic volatile organic compounds (VOC): An overview on emission. physiology and ecology, J. Atmos. Chem., 33, 23-88, 1999.

Kulmala, M., Rannik, Ü., Zapadinsky, E. L., Clement, C. F.: The ef- 
fect of saturation fluctuations on droplet growth, J. Aerosol Sci., 28, 1395-1409, 1997.

Kulmala, M., Toivonen, A., Mäkelä, J. M., and Laaksonen, A.: Analysis of the growth of nucleation mode particles observed in the Boreal forest, Tellus, 50B, 449-462, 1998.

Kulmala, M., Pirjola, L., and Mäkelä, J. M.: Stable sulphate clusters as a source of new atmospheric particles, Nature, 404, 66-69, 2000.

Kulmala, M., Hämeri, K., Aalto, P. P., Mäkela, J.M., Pirjola, L., Nilsson, E. D., Buzorius, G., Rannik, Ü., Dal Maso, M., Seidl, W., Hoffman, T., Janson, R., Hansson, H.-C., Viisanen, Y., Laaksonen, A., and O'Dowd, C. D.: Overview of the international project on biogenic aerosol formation in the boreal forest (BIOFOR), Tellus, 53B, 324-343, 2001.

Kulmala, M., Dal Maso, M., Mäkelä, J. M., Pirjola, L., Väkevä, M., Aalto, P., Miikkulainen, P., Hämeri, K., and O'Dowd, C. D.: On the formation. growth and composition of nucleation mode particles, Tellus, 53B, 479-490, $2001 \mathrm{~b}$.

Kulmala, M., Kerminen, V.-M., Anttila, T., Laaksonen, A., O'Dowd, C. D.: Organic aerosol formation via sulphate cluster activation, J. Geophys. Res., 109, doi:10.1029/2003JD003961, 2004.

Laaksonen, A., Korhonen, P., Kulmala, M., and Charlson, R. J.: Modification of the Köhler equation to include soluble trace gases and slightly soluble substances, J. Atmos. Sci., 55, 853862,1998

Leaitch, W. R., Bottenheim, J. W., Biesenthal, T. A., Li, S.-M., Liu, P. S. K., Asalian, K., Dryfhout-Clark, H., Hopper, F., and Brechtel, F.: A case study of gas-to-particle conversion in an eastern Canadian forest, J. Geophys. Res., 104, 8095-8111, 1999.

Marti, J. J., Weber, R. J., McMurry, P. H., Eisele, F., Tanner, D., Jefferson, A.: New particle formation at a remote continental site: Assessing the contributions of $\mathrm{SO}_{2}$ and organic precursors, J. Geophys. Res., 102, 6331-6339, 1997.

Mäkelä, J. M., Dal Maso, M., Pirjola, L., Keronen, P., Laakso, L., Kulmala, M., Laaksonen, A.: Characteristics of the atmospheric particle formation events observed at a borel forest site in Southern Finland, Boreal. Environ. Res., 5, 299-313, 2000.

Nilsson, E. D., Rannik, Ü, Kulmala, M., Buzorius, G., and O’Dowd, C. D.: Effects of continental boundary layer evolution, convection, turbulence and entrainment on aerosol formation, Tellus, 53B, 441-461, 2001.

O'Dowd, C. D., Geever, M., Hill, M. K., Smith, M. H., and Jennings, S. G.: New particle formation: Nucleation rates and spatial scales in the clean marine coastal environment, Geophys. Res. Lett., 25, 1661-1664, 1998.

O'Dowd, C. D.: Biogenic coastal aerosol production and its influence on aerosol radiative properties, J. Geophys. Res., 106, 1545-1549, 2001.
O’Dowd, C. D., Aalto, P., Hämeri, K., Kulmala, M., Hoffmann, T.: Aerosol formation: Atmospheric particles from organic vapours, Nature, 416, 497-498, 2002.

Peeters, J., Vereecken, L., and Fantechi, G.: The detailed mechanism of the $\mathrm{OH}$-initiated atmospheric oxidation of $\alpha$-pinene: a theoretical study, Phys. Chem. Chem. Phys., 3, 5489-5504, 2001.

Petersen, D., Ortner, R., Vrtala, A., Wagner, P. E., Kulmala, M., and Laaksonen, A.: Soluble-insoluble transition in binary heterogeneous nucleation, Phys. Rev. Lett., 87, doi:10.1103/PhysRevLett.87.225703, 2001.

Seinfeld, J. H. and Pandis, S. N.: Atmospheric Chemistry and Physics: From Air Pollution to Climate Change, John Wiley, New York, 1998.

Sheehan, P. E. and Bowman, F. M.: Estimated effects of temperature on secondary organic aerosol concentrations, Atmos. Env., 35, 2129-2135, 2002.

Strader, R., Lurmann, F., and Pandis, S. N.: Evaluation of secondary organic aerosol in winter, Atmos. Env., 33, 4849-4863, 2000.

Tang, I. N. and Munkelwitz, H R.: Water activities, densities and refractive indices of aqueous sulfates and sodium nitrate droplets of atmospheric importance, J. Geophys. Res., 99, 18 801-18 808, 1994.

Tobias, H. J. and Ziemann, P. J.: Thermal desorption mass spectrometric analysis of organic aerosol formed from reactions of 1-Tetradecene and $\mathrm{O}_{3}$ in the presence of alcohols and carboxylic acids, Environ. Sci. Technol., 34, 2105-2115, 2000.

Tobias, H. J., Doherty, K. S., Beving, D. E., and Ziemann, P. J.: Effect of relative humidity on the chemical composition of secondary organic aerosol formed from reactions of 1-Tetradecane and $\mathrm{O}_{3}$, Environ. Sci. Technol., 34, 2116-2125, 2000.

Weber, R. J., Marti, J. J., McMurry, P. H., Eisele, F. L., Tanner, D. J., and Jefferson, A.: Measurements of new particle formation and ultrafine particle growth rates at a clean continental site, J. Geophys. Res., 102, 4375-4385, 1997.

Wexler, A. S., Lurmann, F. W., and Seinfeld, J. H.: Modelling urban and regional aerosols - I. Model Development, Atmos. Env., 28, 531-546, 1994.

Yu, J., Griffin, R. J., Cocker III, D. R., Flagan, R. C., Seinfeld, J. H., Blanchard, P.: Observations of gaseous and particulate products of monoterpene oxidation in forest atmospheres, Geophys. Res. Lett., 26, 1145-1148, 1999.

Zhang, Y., Seigneur, C., Seinfeld, J. H., Jacobson, M. Z., and Binkowski, F.: Simulation of aerosol dynamics: A comparative review of algorithms used in air quality models, Aerosol. Sci. Technol., 31, 487-514, 1999.

Ziemann, P. J.: Evidence for low-volatility diacyl peroxides as a nucleating agent and major component of aerosol formed from reactions of $\mathrm{O}_{3}$ with cyclohexene and homologous compounds, J. Phys. Chem., 106, 4390-4402, 2002. 